\title{
Changes in Self-Stimulation Response during Chronic Morphine Treatment and after Withdrawal of Morphine in Rats
}

\author{
Chiaki Kamei \\ Department of Pharmacology, Faculty of Pharmaceutical Sciences, Okayama University, Okayama 700, Japan
}

Received June 16, $1994 \quad$ Accepted July 19, 1994

\begin{abstract}
Morphine $(5-20 \mathrm{mg} / \mathrm{kg}$, s.c.) dose-dependently inhibited the hypothalamic self-stimulation response 1-2 hr after administration of the drug. Thereafter, slight increase in the self-stimulation response was seen $4-8 \mathrm{hr}$ after drug administration. The depressant effect induced by $10 \mathrm{mg} / \mathrm{kg}$, s.c. of morphine on the self-stimulation response was antagonized by $1 \mathrm{mg} / \mathrm{kg}$, s.c. of levallorphan. Repeated administration of morphine $(10 \mathrm{mg} / \mathrm{kg}$, s.c.) resulted in an increase of the self-stimulation response. The self-stimulation response rate was increased significantly 24 and $48 \mathrm{hr}$ after withdrawal of morphine in chronic-morphinetreated rats; In these rats, the initial dose of morphine $(10 \mathrm{mg} / \mathrm{kg}$, injected s.c. twice daily 7 days a week) was increased gradually until at the end of 5 weeks, each dose was $50 \mathrm{mg} / \mathrm{kg}$, s.c.
\end{abstract}

Keywords: Self-stimulation, Morphine, Withdrawal sign

In the self-stimulation study, the animal presses the lever without ceasing to receive the electrical stimulation in the rewarding area of the brain (1). The lever pressing response in self-stimulation seems to be quite similar to the behavior in which the animal desires to continue opiate administration. On the other hand, it has been reported that the self-stimulation response is initially depressed by doses of morphine above $5.0 \mathrm{mg} / \mathrm{kg}(2)$, after which a delayed rebound increase in response may follow (3).

The purpose of this study was to examine the changes in self-stimulation response after withdrawal of drugs in morphine-dependent rats. The effects of single and repeated administrations of morphine on hypothalamic selfstimulation were also investigated.

The subjects were male Wistar HLA strain rats weighing $250-300 \mathrm{~g}$. The animals were housed individually in a room illuminated from 8:00 A.M. to 6:00 P.M. Room temperature was maintained at $23 \pm 1{ }^{\circ} \mathrm{C}$ with $65 \pm 5 \%$ relative humidity. Food and water were available ad libitum. The procedure of surgery was as follows: Bipolar stainless steel electrodes $(200 \mu \mathrm{m}$ in diameter, tip distance of $0.5-0.8 \mathrm{~mm}$ ) were implanted stereotaxically in the posterolateral hypothalamus under pentobarbital anesthesia. The coordinates were $0.5 \mathrm{~mm}$ posterior to the bregma, $1.8 \mathrm{~mm}$ lateral to the midline and $8.0 \mathrm{~mm}$ deep from the surface of the cortex, according to the atlas of de Groot (4). The experimental chamber was a modified Skinner box. The side and front walls (containing a door) were composed of clear plexiglas, while the remaining walls were constructed of white plexiglas. The floor was covered with a black rubber plate. A stainless steel lever $(2.5-\mathrm{cm}$-thick and 6.5 -cm-wide) protruded $2.5 \mathrm{~cm}$ through the right wall and a red lamp was placed just above the lever. A train of $60-\mathrm{Hz}$ sinusoidal waves of $20-50 \mu \mathrm{A}$ was delivered for $0.25 \mathrm{sec}$ with each lever pressing. The drugs used were morphine hydrochloride (Dainippon, Osaka) and levallorphan tartrate (Takeda, Osaka), all of which were administered s.c. In the tests of single and repeated administrations of morphine, the rats that showed a constant lever pressing response of $60-100 / \mathrm{min}$ at $50 \mu \mathrm{A}$ were selected for the drug test. Eight rats were used for each group. In the withdrawal test, 24 rats were used, and they were divided into 3 groups: low $(10-20$ responses $/ \min$ at $20 \mu \mathrm{A})$, median $(30-50$ responses $/ \mathrm{min}$ at $30 \mu \mathrm{A})$ and high $(80-100$ responses $/ \mathrm{min}$ at $50 \mu \mathrm{A}$ ) rate response groups.

One-way analysis of variance with Dunnett's test was used to determine statistical significance.

Morphine dose-dependently inhibited the hypothalamic self-stimulation response. At a dose of $5 \mathrm{mg} / \mathrm{kg}$, the drug elicited a significant depression $1 \mathrm{hr}$ after administration. At doses of 10 and $20 \mathrm{mg} / \mathrm{kg}$, a significant inhibition was observed 1 and $2 \mathrm{hr}$ after drug administration, respectively. At 4-8 hr after morphine administration, the drug caused an increase of response in all doses used, but no significant effect was observed (Fig. 1A). The inhibitory 


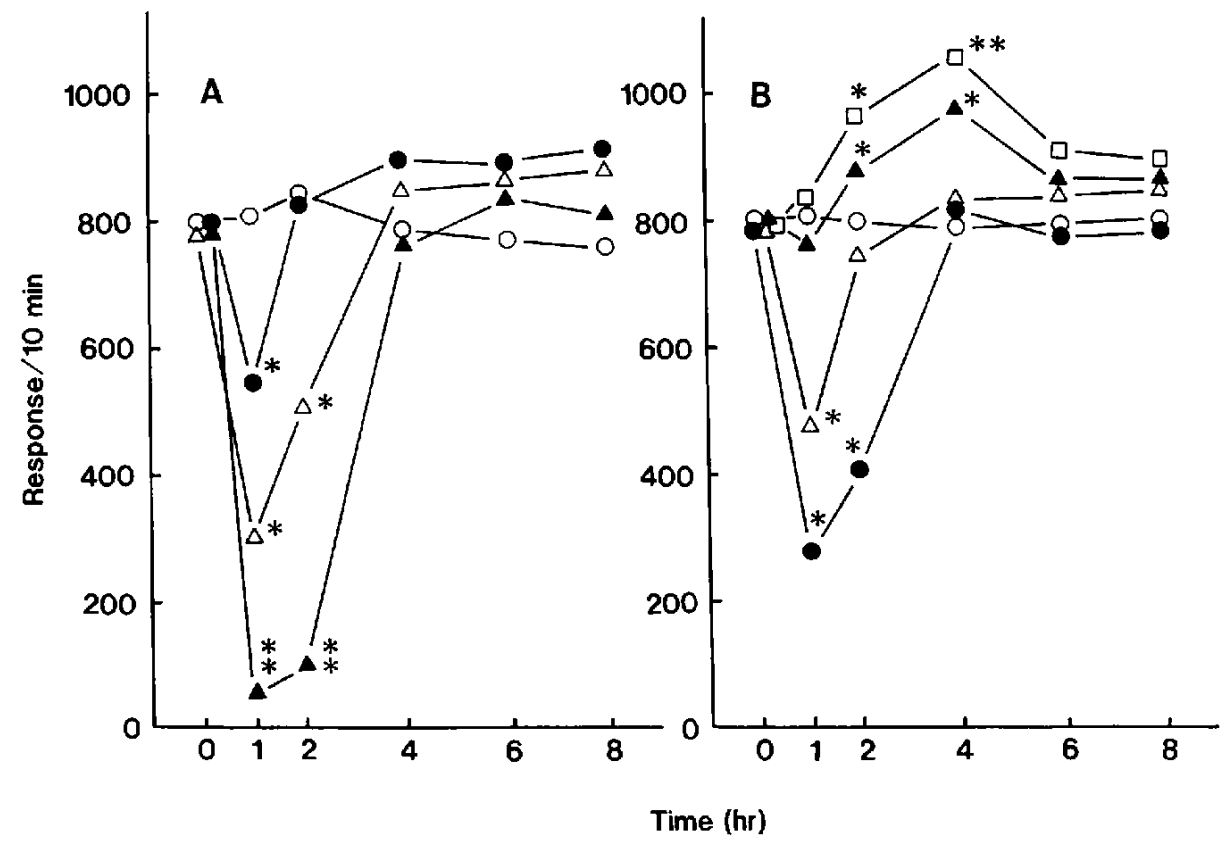

Fig. 1. Effects of single and repeated administrations of morphine on hypothalamic self-stimulation behavior. A: Single administration. $\bigcirc$, saline;, $5 \mathrm{mg} / \mathrm{kg} ; \wedge, 10 \mathrm{mg} / \mathrm{kg} ; \boldsymbol{\Delta}, 20 \mathrm{mg} / \mathrm{kg}$. B: Repeated administration. $\bigcirc$, saline;, Day $1 ; \triangle$, Day 3; $\Delta$, Day 7; $\square$, Day 10. ${ }^{* * *}$ : Significantly different from the saline-treated control group with $\mathrm{P}<0.05$ and $\mathrm{P}<0.01$, respectively.

effect induced by $10 \mathrm{mg} / \mathrm{kg}$ of morphine on this response was antagonized entirely by pretreatment with $1 \mathrm{mg} / \mathrm{kg}$ of levallorphan, and a significant effect was observed 1 and $2 \mathrm{hr}$ after drug administration in the morphine-alonetreated group. In the repeated administration study, morphine was injected at a dose of $10 \mathrm{mg} / \mathrm{kg}$ for 10 days. On the 1st day, the self-stimulation response was decreased significantly 1 and $2 \mathrm{hr}$ after drug administration. On the 3rd day, the inhibition of self-stimulation was attenuated; and on the 7 and 10th days, the depressant effect of morphine on this response was abolished, and a significant facilitatory effect appeared 2 and $4 \mathrm{hr}$ after morphine treatment (Fig. 1B). In the morphine withdrawal test, rats were made tolerant to morphine in the following manner: the initial dose of morphine $(10 \mathrm{mg} / \mathrm{kg}$, injected s.c. twice daily 7 days a week) was increased gradually until at the end of 5 weeks, each dose was $50 \mathrm{mg} / \mathrm{kg}$, administered as described above. During morphine treatment, the selfstimulation response was tested $12 \mathrm{hr}$ after administration of morphine on days $7,14,21,28$ and 35 . On day 36 , a withdrawal state was induced by withdrawaling morphine. As shown in Fig. 2A, the self-stimulation response was not changed during morphine treatment in all groups. However, the self-stimulation response was significantly increased 24 and $48 \mathrm{hr}$ after withdrawal of morphine. In addition, $2 \mathrm{hr}$ after administration of morphine $(10 \mathrm{mg} / \mathrm{kg}$, s.c.), the increase in self-stimulation response was abolished (Fig. 2B).
In this study, it was found that morphine showed both inhibitory and excitatory effects on the self-stimulation response, and development of tolerance to the suppressive effect was also observed. These results were essentially in accord with observations by Adams et al. (3). However, the facilitatory effect by single administration of morphine was somewhat weak compared with the finding of Adams et al. (3). It is well known that there are good correlations between the self-stimulation response and brain catecholamine levels. For instance, amphetamine increased the self-stimulation response and reserpine decreased the self-stimulation response $(5,6)$. On the other hand, Akera and Brody (7) reported that brain noradrenaline level was increased during chronic morphine treatment.

Interestingly, it was also found that the self-stimulation response was increased significantly 24 and $48 \mathrm{hr}$ after withdrawal of morphine. At the same times, withdrawal signs such as decrease of body weight, diarrhea, piloerection and wet dog behavior were also detected. It is well known that withdrawal signs by natural withdrawal of morphine peaked $24-48 \mathrm{hr}$ after withdrawal of morphine. Therefore, it seems likely that the increase in response rate after withdrawal of narcotics was a result of the withdrawal state. As shown in Fig. 2B, the effects observed in the low and median response groups were more obvious than that seen in the high response group. The high response group showed less effect than the other two 
A

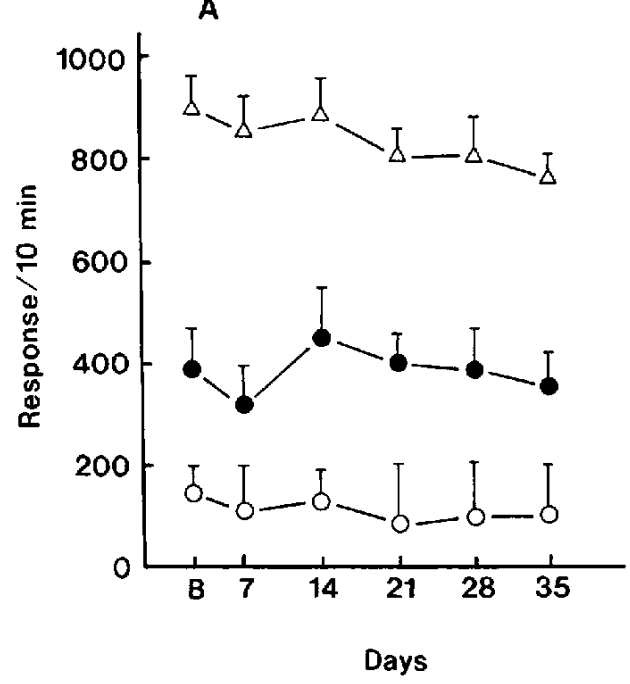

B

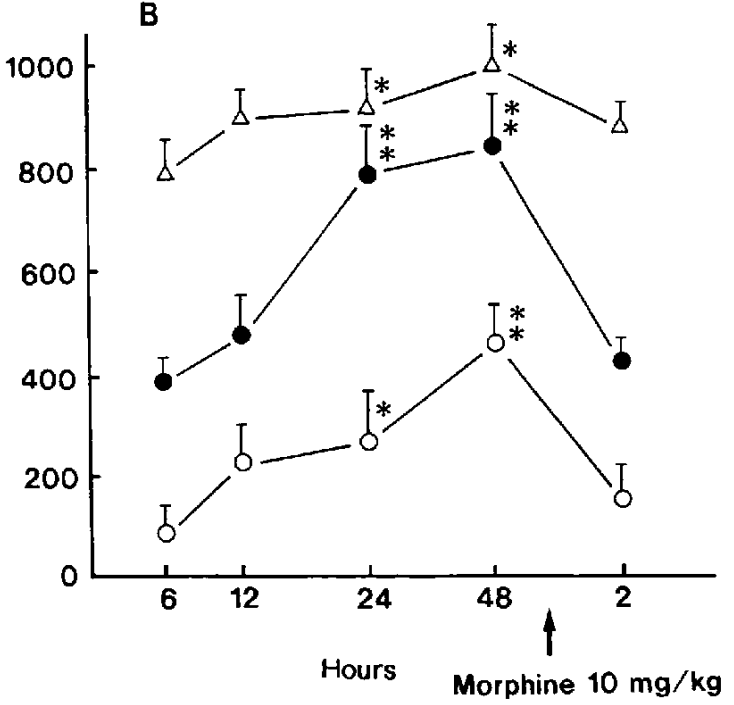

Fig. 2. Changes in self-stimulation response during chronic administration of morphine and after withdrawal of morphine. A: Chronic administration. $\bigcirc, 20 \mu \mathrm{A} ; 0,30 \mu \mathrm{A} ; \triangle, 50 \mu \mathrm{A}$. Self-stimulation response was tested $12 \mathrm{hr}$ after administration of morphine on days $7,14,21,28$ and 35. B: After withdrawal of morphine. $\bigcirc, 20 \mu \mathrm{A} ; \mathrm{O}, 30 \mu \mathrm{A} ; \triangle, 50 \mu \mathrm{A}$. Self-stimulation response was tested $6,12,24$ and $48 \mathrm{hr}$ after morphine $(50 \mathrm{mg} / \mathrm{kg})$ treatment. ${ }^{*}, * *$ : Significantly different from the values at $6 \mathrm{hr}$ after administration of $50 \mathrm{mg} / \mathrm{kg}$ of morphine with $\mathrm{P}<0.05$ and $\mathrm{P}<0.01$, respectively.

groups because the self-stimulation rate in this group had already reached its maximum. In the interaction between withdrawal signs and brain catecholamine level, Gunne (8) described that noradrenaline level of the brain was significantly decreased during the withdrawal period. Akera and Brody (7), on the contrary, described that there is no relationship between the addiction cycle and the levels of brain catecholamines. Sloan et al. (9) also reported that the brain noradrenaline level was not changed after withdrawal of morphine. Therefore, monitoring the brain catecholamine level may not be a good parameter for determining the increase in self-stimulation response after withdrawal of morphine. On the other hand, Babbini et al. (10) reported in a fixed-interval schedule experiment that an increase in lever pressing was exhibited by withdrawal of morphine. Collins and Weeks (11) also reported that continuous intravenous infusion of morphine decreases and nalorphine increases the voluntary morphine intake in dependent rats maintained with $10 \mathrm{mg} / \mathrm{kg}$ of morphine on a fixed-ratio reinforcement schedule of 10 (FR-10). From these findings, an increase in self-stimulation response observed after withdrawal of morphine seems to suggest that the electrical stimulation of the reward area has the same effect as the morphine intake.

\section{REFERENCES}

1 Olds $\mathrm{J}$ and Milner P: Positive reinforcement produced by electrical stimulation of septal area and other regions of rat brain.
J Comp Physiol 47, 419-427 (1954)

2 Olds $\mathbf{J}$ and Travis RP: Effects of chlorpromazine, meprobamate, pentobarbital and morphine on self-stimulation. J Pharmacol Exp Ther 128, 397-404 (1960)

3 Adams WJ, Lorens SA and Mitchell CL: Morphine enhances lateral hypothalamic self-stimulation in the rat. Proc Soc Exp Biol 140, 770-771 (1972)

4 de Groot $\mathrm{J}$ : The rat forebrain in stereotaxic coordinates. Trans Royal Neth Acad Sci 52, 1-40 (1959)

5 Stein L: Self-stimulation of the brain and the central stimulant action of amphetamine. Fed Proc 23, 836-850 (1964)

6 Stinus L, Thierry AM and Cardo B: Effects of various inhibitors of tyrosine hydroxylase and dopamine beta-hydroxylase on rat self-stimulation after reserpine treatment. Psychopharmacology (Berlin) 45, 287-294 (1976)

7 Akera T and Brody TM: The addiction cycle to narcotics in the rat and its relation to catecholamines. Biochem Pharmacol 17, $675-688$ (1968)

8 Gunne L-M: Noradrenaline and adrenaline in the rat brain during after acute and chronic morphine administration and during withdrawal. Nature 184, 1950-1951 (1959)

9 Sloan JW, Brooks JW, Eisenman AJ and Martin WR: The effect of addiction to and abstinence from morphine on rat tissue catecholamine and serotonin levels. Psychopharmacology (Berlin) 4, $261-270$ (1963)

10 Babbini $M$, Gaiardi $M$ and Bartoletti $M$ : Changes in fixed-interval behavior during chronic morphine treatment and morphine abstinence in rats. Psychopharmacology (Berlin) 45, 255-259 (1976)

11 Collins RJ and Weeks JR: Lack of effect of dexoxadrol in selfmaintained morphine dependence in rats. Psychopharmacology (Berlin) 11, 287-292 (1967) 